X-ray and neutron sensitivity of imaging plates

N. Izumi, J. Lee, E. Romano, G. Stone, B. Maddox, T. Ma, V. Rekow, D. K. Bradley, P. Bell

September 3, 2013

SPIE

San Diego, CA, United States

August 27, 2013 through August 27, 2013 
This document was prepared as an account of work sponsored by an agency of the United States government. Neither the United States government nor Lawrence Livermore National Security, LLC, nor any of their employees makes any warranty, expressed or implied, or assumes any legal liability or responsibility for the accuracy, completeness, or usefulness of any information, apparatus, product, or process disclosed, or represents that its use would not infringe privately owned rights. Reference herein to any specific commercial product, process, or service by trade name, trademark, manufacturer, or otherwise does not necessarily constitute or imply its endorsement, recommendation, or favoring by the United States government or Lawrence Livermore National Security, LLC. The views and opinions of authors expressed herein do not necessarily state or reflect those of the United States government or Lawrence Livermore National Security, LLC, and shall not be used for advertising or product endorsement purposes. 


\title{
X-ray and neutron sensitivity of imaging plates
}

\author{
N. Izumi*a ${ }^{\text {, J. Lee }}{ }^{\text {b }}$ E. Romano ${ }^{\text {b }}$, G. Stone ${ }^{\text {a }}$, B. Maddox ${ }^{\text {a }}$, T. Ma ${ }^{\text {a }}$, V. Rekow ${ }^{\text {a }}$, \\ D. K. Bradley ${ }^{\text {a }}$, P. Bell ${ }^{\text {a }}$ \\ ${ }^{a}$ Lawrence Livermore National Laboratory, 7000 East Avenue, Livermore, CA, 94550; \\ ${ }^{\mathrm{b}}$ National Security Technologies, 161 S Vasco Road, Livermore, CA, 94551;
}

\begin{abstract}
Periodic sensitivity calibration of imaging plates (IP) is crucial for quantitative understanding of $\mathrm{x}$-ray data obtained at the National Ignition Facility (NIF). To test the x-ray sensitivity of the IPs and the scanners, we developed an X-ray exposure station based on radioactive isotopes $(55 \mathrm{Fe}, 109 \mathrm{Cd}$, and $241 \mathrm{Am})$. This apparatus provides a convenient setup for a periodical test of the IP's and the scanners. On NIF implosion experiments with deuterium-tritium mixture fuel, the neutrons produced in the capsule hit the imaging plates and impose background signal. Therefore it is also important to know the neutron sensitivity of the IPs. The sensitivity for $14 \mathrm{MeV}$ neutrons was measured on high neutron yield shots at the OMEGA laser facility. The measured sensitivities were compared with the results of Monte Carlo simulations.
\end{abstract}

Keywords: imaging plate, $x$-ray imaging, neutron background, MCNP, MCNPX

\section{INTRODUCTION}

An imaging plate (IP) is a phosphor which has a signal-storage capability [1]. Due to its immunity to electric-magneticinterference, IPs have been used in various laser-plasma experiments $[2,3,4,5]$. When an IP is exposed to ionizing radiation, electrons excited in the phosphor $(\mathrm{BaFBr}: \mathrm{Eu})$ are trapped by color centers. When the plate is scanned with a laser beam $(650 \mathrm{~nm})$, those trapped electrons are re-excited and cause photo-stimulated luminescence $(\sim 390 \mathrm{~nm})$ by recombination [6]. Each type of IP has a different composition and physical thickness. The readout efficiency of the stored signal also depends on laser power, spot size, and scanning speed of the scanner. A signal fading due to thermal excitation of trapped carrier also affects the sensitivity of IPs. To keep the consistency, the sensitivity calibration has to be done with the same conditions of the actual usage.

\section{X-RAY EXPOSURE STATION}

Fig. 1 (a) is the exploded view of the $\mathrm{x}$-ray exposure station. To minimize leakage of the radiation, most parts of the station are made of tungsten alloy. The station can hold up to 5 radioactive isotopes (RI). Currently it has 3 sources. For reduction of fluorescence from the tungsten alloy parts, the pockets for the RI sources have $5 \mathrm{~mm}$ apertures at the bottom. The duration of exposure is controlled by the sliding shutter. To have similar exposure from sources which have different activities, users can adjust the distance between the source to the IP $(13.48 \mathrm{~mm}, 23.48 \mathrm{~mm}$ or $33.4 \mathrm{~mm})$. Imaging plates were inserted to the slot below the filter pocket. In order to reduce the exposure of lower energy x-ray lines from the 241 Am source (L fluorescence lines from Np on 13.9, 17.8 and $20.8 \mathrm{keV}$ ), a $2 \mathrm{~mm}$ thick aluminum filter was installed in the filter pocket. The diameter of the active area of these sources (Eckert\& Ziegler Type M) should be less than $3 \mathrm{~mm}$. However we found the active area of those sources are larger than $5 \mathrm{~mm}$. Therefore, we measured the fraction of the source activities inside the $5 \mathrm{~mm}$ aperture and used that for estimation of the $\mathrm{x}$-ray photon fluence at the IP. Table 1 shows the details of this experiment. The setup parameters of the IP scanner are summarized on the table 2 . 

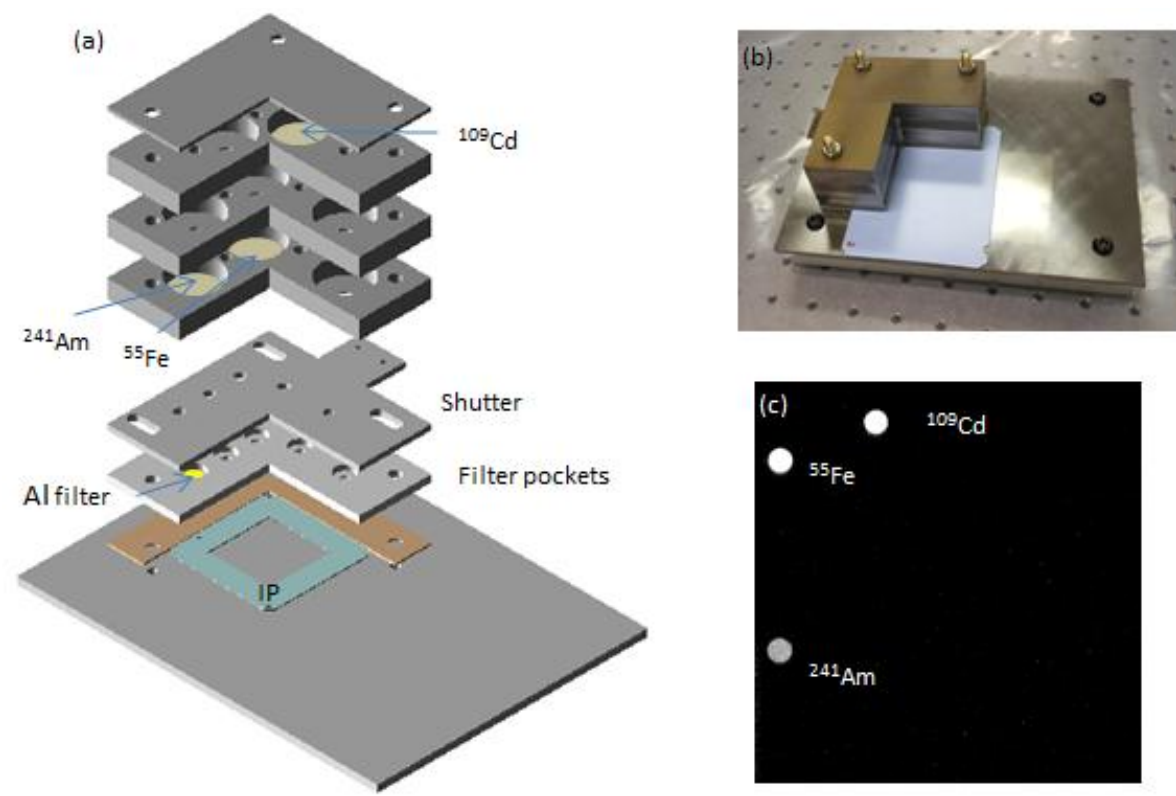

Fig. 1. Exploded view of the exposure station (a), photo during x-ray exposure (b), scanned data (c).

Table 1 . Summary of the $\mathrm{x}$-ray sensitivity calibration

\begin{tabular}{|c|c|c|c|}
\hline Source & $55 \mathrm{Fe}$ & 109Cd & 241Am \\
\hline Serial No & $1468-874$ & $1531-2-1$ & $1531-2-2$ \\
\hline Activity as of 5/14/2012 [kBq] & 2659 & 2676 & 368 \\
\hline Distance between source and IP (mm) & 13.8 & 33.7 & 13.8 \\
\hline Duration of exposure (sec) & 300 & 300 & 300 \\
\hline Time from start of exposure to scan (min) & $\begin{array}{l}17.52,52.0 \\
52.67,20.77\end{array}$ & $\begin{array}{l}17.52,52.0 \\
52.67,20.77\end{array}$ & $\begin{array}{l}17.52,52.0 \\
52.67,20.77\end{array}$ \\
\hline Filter material & Air & Air & Air $+\mathrm{Al} 2 \mathrm{~mm}$ \\
\hline Transmission though filter & $95.8 \%$ & $99.7 \%$ & $85.8 \%$ \\
\hline Fraction of activity in $5 \mathrm{~mm}$ aperture & $61.5 \%$ & $74.8 \%$ & $98.9 \%$ \\
\hline $\mathrm{X}$-ray energy (keV) & $\begin{array}{l}5.888, \quad 5.899, \\
6.49\end{array}$ & $\begin{array}{l}21.99, \quad 22.163, \\
24.912,24.943, \\
25.455\end{array}$ & 59.541 \\
\hline Photons per decay & 0.27725 & 1.0221 & 0.359 \\
\hline Photon fluence (photons $/ \mathrm{mm}^{2}$ ) & $5.68 \times 10^{4}$ & $4.30 \times 10^{4}$ & $1.41 \times 10^{4}$ \\
\hline Averaged signal $\left(\mathrm{PSL} / \mathrm{mm}^{2}\right) *$ & 78.4 & 66.4 & 12.52 \\
\hline Sensitivity (PSL/photon) & $1.38 \times 10^{-3}$ & $1.54 \times 10^{-3}$ & $0.888 \times 10^{-3}$ \\
\hline
\end{tabular}

*The results of the 4 samples were averaged after the fade correction (equivalent to the signal of the plates which scanned $20 \mathrm{~min}$ from the start of exposure). 
Table 2. Setup the IP scanner used for the x-ray sensitivity calibration

\begin{tabular}{cc}
\hline Parameters & Value \\
\hline IP Type & BAS SR (S/N 5x440024) \\
Scanner & FUJIFILM FLA 7000 S/N \\
& 7662179 \\
Pixel Size & $25 \mu \mathrm{m}$ \\
Pixel Depth & $16 \mathrm{bit}$ \\
Sensitivity & 4000 \\
Latitude & 5 \\
Shading data* & IP_2009-10-06T11:27:54 \\
\hline
\end{tabular}

*Name of the shading data file is useful for tracing of service/calibration date of the scanner

\section{MONTE CARLO MODELING OF THE X-RAY SENSITIVITY}

In order to understand the physics which governs the spectral sensitivity, we did numerical modeling of the imaging plate by using MCNPX [7]. Table 3 summarizes the material composition of the imaging plate assumed in the MCMPX model. Similar to other radiation detectors, the strength of the imaging plate signal is proportional to the energy deposited in the phosphor layer, and hence it is important to calculate how much energy is deposited in the phosphor layer.

Interactions of $\mathrm{x}$-ray photons in the imaging plate can be described as follows. When x-ray photon energy is below 100 $\mathrm{keV}$, the photoelectric absorption is dominant. In this region, it is important to calculate how much energy escapes the phosphor region as $\mathrm{x}$-ray fluorescence. For example, when a $40 \mathrm{keV}$ photon is absorbed by k-shell of a Ba atom, 37.4 $\mathrm{keV}$ of photon energy is used for ionization of the atom and the kinetic energy given to the photo electron is about 2.6 $\mathrm{keV}$. Then the atom captures an electron from surroundings and emits several fluorescence photons or Auger electrons. Some fraction of the fluorescence photons escapes the phosphor without depositing energy in the phosphor (i.e. Fluorescence loss).When $\mathrm{x}$-ray energy is higher than $100 \mathrm{keV}$, the contribution of Compton recoil is getting more important. In this energy region, the stopping range of the Compton electrons exceeds the thickness of the phosphor layer $\left(\sim 34 \mathrm{mg} / \mathrm{cm}^{2}\right)$ and they escape with depositing part of their kinematic energy in the phosphor (i.e. Electron escape). In order to include those deficiencies, the MCNPX was configured to track both photons and electrons (MODE P E). The signal strength was estimated by calculating energy deposited by electrons generated during photon collisions (tally6:e).

Another important mechanism which affects the spectral sensitivity is a depth-dependent readout efficiency of the laser scanner. Low energy $\mathrm{x}$-ray photons (below few $\mathrm{keV}$ ) are absorbed in the shallow surface of the phosphor and higher energy photons (over $20 \mathrm{keV}$ ) penetrate through and excite the entire volume of the phosphor. When we scan the plate with laser light, the readout efficiency of the deep layer is lower than that on the shallow surface because of the diffusive transport of visible light in the phosphor. It should be noted that not only the laser light $(650 \mathrm{~nm})$ but also the photostimulated luminescence signal $(\sim 390 \mathrm{~nm}$,) is scattered by the granular structure of the phosphor. Therefore due to this depth effect, sensitivity for high x-ray energy should be reduced compared that for the lower energy x-ray. Detailed transport of the laser light and the photo-stimulated luminescence in the phosphor was described by M. Thoms in reference 8. For ease of calculation, we model the layer dependent readout efficiency as,

$$
\eta(z, \lambda)=\exp (-z / L)
$$

where $\mathrm{z}$ is the depth from the phosphor surface, $\mathrm{L}$ is the characteristic depth of the readout. In order to account for the depth effect, the phosphor layer in the MCNPX model is divided into 6 layers and the sensitivity of the entire plate is calculated as, 


$$
\xi_{\text {total }}(h v)=\frac{1}{W} \int_{0}^{d} \eta(z, L) \frac{d E(z, h v)}{d z} d z
$$

where $\mathrm{dE} / \mathrm{dz}$ is the energy deposition in the phosphor per incident photon calculated by MCNPX, $\mathrm{d}$ is the thickness of the phosphor $(112 \mu \mathrm{m})$, and $\mathrm{W}$ is energy deposition (at the shallow surface) which corresponds to the scanner readout of 1 PSL. Figure 2 shows the comparison of experimental data and the model calculated by Eq. (2). We fit the experimental data points by adjusting $\mathrm{W}$ and $\mathrm{L}$. All the experimental data points were consistently explained by the model when $\mathrm{W}=4.12 \mathrm{MeV}$ and $\mathrm{L}=60 \mu \mathrm{m}$.

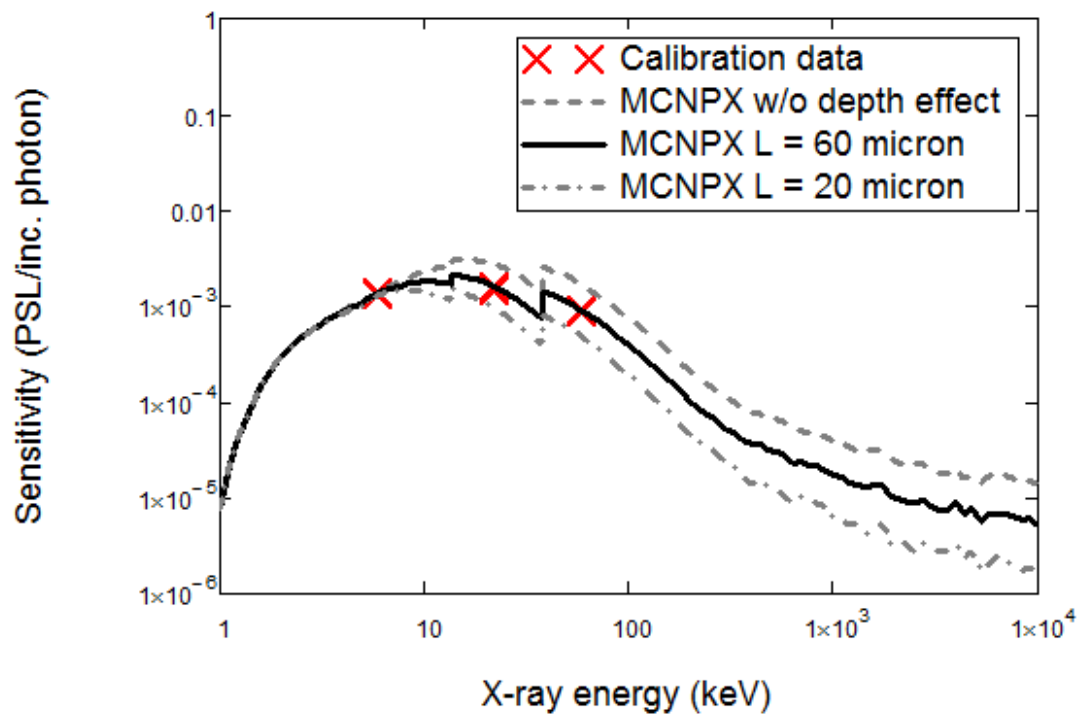

Fig. 2. Comparison of experimental data and MCNPX model. The MCNPX model showed good agreement with the experiment when $\mathrm{W}=4.12 \mathrm{MeV}$ and $\mathrm{L}=60 \mu \mathrm{m}$.

Table 3. Material composition of the BAS SR plate used in the MCNPX calculation

\begin{tabular}{ccc}
\hline Layer & $\begin{array}{c}\text { Composition } \\
\text { (Atomic ratio) }\end{array}$ & $\begin{array}{c}\text { Thickness } \\
\left(\mathrm{mg} / \mathrm{cm}^{2}\right)\end{array}$ \\
\hline Protective coat & $\mathrm{H}-8, \mathrm{C}-10, \mathrm{O}-4$ & 1.192 \\
Phosphor & $\mathrm{Ba}-1, \mathrm{~F}-1, \mathrm{Br}-1, \mathrm{C}-2.364, \mathrm{H}-3.547, \mathrm{~N}-$ & 34.384 \\
& $0.591, \mathrm{O}-0.296$ & 1.676 \\
\hline $\begin{array}{c}\text { Undercoat } \\
\text { Base }\end{array}$ & $\mathrm{H}-8, \mathrm{C}-10, \mathrm{O}-4$ & 26.543 \\
Ferrite gum & $\mathrm{H}-8, \mathrm{C}-10, \mathrm{O}-4$ & 24.0 \\
\hline Back protective & $\mathrm{H}-1, \mathrm{Fe}-2, \mathrm{O}-4, \mathrm{C}-3.02, \mathrm{H}-4.832$ & 3.493 \\
\hline
\end{tabular}


(a)

(b)

Fiber optical face plate

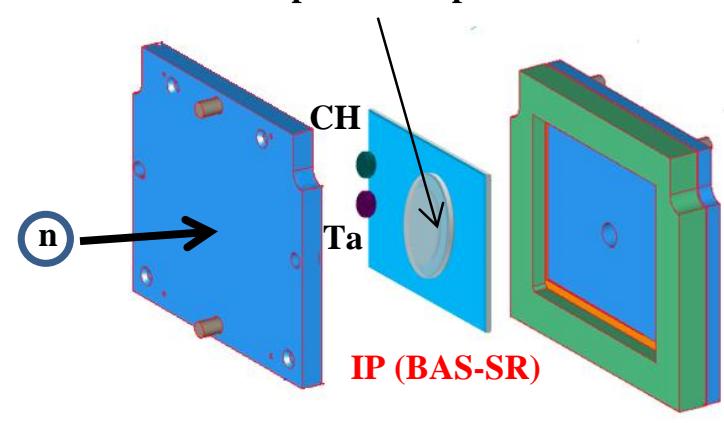

Under the $\mathrm{CH}$ disc,

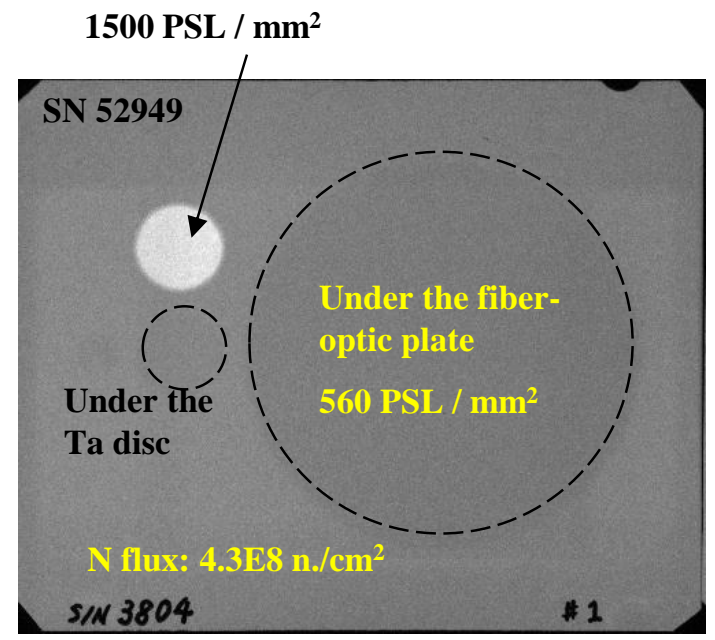

Fig. 3. Experimental setup of the neutron sensitivity measurement (a). Typical data after neutron exposure (b).

\section{NEUTRON SENSITIVITY MEASURMENT}

The neutron sensitivity of the IP (BAS SR plate) was measured at the OMEGA laser facility at the University of Rochester [9]. Neutrons (14 MeV) produced in the imploded capsules were used for excitation of the phosphor. Figure 3 shows the experimental setup. The imaging plate was enclosed in a light-tight cassette made of aluminum alloy and located on distance $\mathrm{R}=43.2 \mathrm{~cm}$ from the target chamber center. Total neutron yield in the imploded plasma (Yn) was monitored by absolutely calibrated time-of-flight scintillation detectors [10]. Neutron fluence $\phi$ at the IP cassette was estimated as $\phi=\mathrm{Yn} /\left(4 \pi \mathrm{R}^{2}\right)$. The imploded capsules produce $\mathrm{x}$-ray background also. To confirm the excitation of the phosphor is dominated by the neutron excitation and contribution of hard $\mathrm{x}$-ray background is small, we covered part of the IP with thick high-Z material (a $0.8 \mathrm{~mm}$ thick tantalum disc and an $8 \mathrm{~mm}$ thick fiber-optic faceplate made of lead glass). A $1 \mathrm{~mm}$ thick plastic resin $(\mathrm{CH})$ disc was used to convert the neutrons to the recoiled protons and enhance the sensitivity under the disc. Table 4 summarizes setup parameters of the IP scan.

Table 4. Setup of IP scanner used for the neutron sensitivity measurement

\begin{tabular}{cc}
\hline Parameters & Value \\
\hline IP Type & BAS SR (S/N 3804) \\
Scanner & FUJIFILM BAS 1800II S/N 462321 \\
Pixel Size & $50 \mu \mathrm{m}$ \\
Pixel Depth & $16 \mathrm{bit}$ \\
Sensitivity & 4000 \\
Latitude & 5 \\
\hline
\end{tabular}

Fig. 3 (b) shows the IP data obtained after the neutron exposure. The tantalum disc and the fiber-optic face plate are optically thick for the x-ray and optically thin for the neutrons. Therefore the observed faint shadows of those materials are suggesting the phosphor excitation is dominated by the neutrons. The background level of the region covered with 
the $1 \mathrm{~mm}$ thick plastic disc got 3 times higher than that of surrounding regions. Typical neutron induced background under the fiber-optic faceplate was $560 \mathrm{PSL} / \mathrm{mm}^{2}$. The neutron fluence on the imaging plate was $4.3 \times 10^{6}$ neutron $/ \mathrm{mm}^{2}$. Therefore the neutron sensitivity at $14 \mathrm{MeV}$ is $1.3 \times 10^{-4} \mathrm{PSL} /$ neutron. Figure 4 shows the observed background and the neutron fluence. The background scales linearly with the neutron fluence. The noise (the fluctuation of the background level in standard deviation) scales with square-root of the neutron fluence. This is consistent with a theoretical model that predicts the noise amplitude is determined by the statistical uncertainty of the neutron events in the spatial resolution elements.

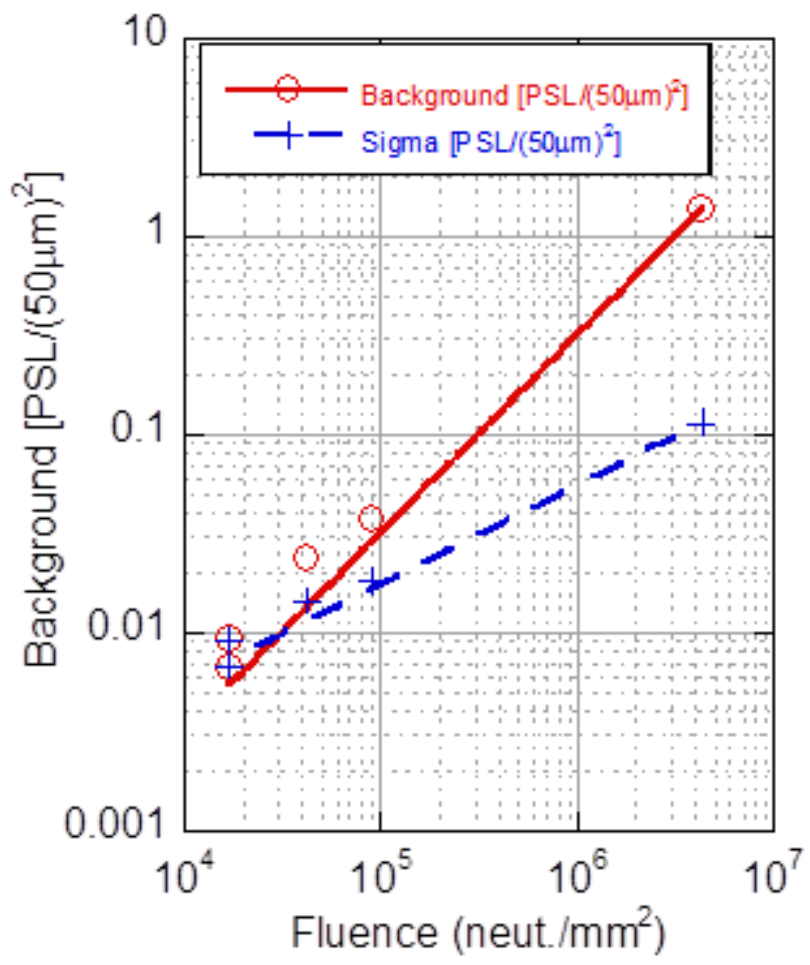

Fig. 4. Neutron fluence vs. observed background and noise (standard deviation of the background).

\section{MODELING OF THE NEUTRON SENSITIVITY}

The mechanism of neutron detection is different from x-ray detection. X-ray photons are converted to electrons that then deposit their kinetic energy in the phosphor. In the case of neutrons, they produce energetic ions in the phosphor region via elastic recoil, $(n, p)$, or $(n, \alpha)$ reactions. Then those energetic ions deposit energy in the phosphor region. Therefore it is important to understand the behavior of the energetic ions in the phosphor layer. In the case of $14 \mathrm{MeV}$ neutron excitation, the stopping range of most recoiled particles is shorter than the thickness of the phosphor layer and they cannot escape. However protons produced by elastic recoil can have energy up to $14 \mathrm{MeV}$ and some of them have enough energy to escape from the phosphor region. Therefore tracking of energetic proton in the phosphor is important. Figure 5 shows the result of numerical modeling and the experimental data. In order to calculate the energy deposition of the energetic protons, the numerical model used the results of MCNP5 [11] together with SRIM [12]. 
First of all, we prepared a hypothetical model of the phosphor which has no hydrogen atoms in the phosphor layer. Then energy deposition to the phosphor was calculated with the MCNP5 (tally type F6:n, track length estimate of heating).

The generation and the slowdown of the recoiled protons were calculated by another 3D Monte Carlo code which based on a stopping-power table generated by SRIM. The total energy deposition to the phosphor was calculated by adding up those two calculations.

Figure 5 shows the result of sensitivity calculation. When the neutron energy is less than $1 \mathrm{MeV}$, the proton recoil in the phosphor layer is the dominant process of energy deposition. When neutron energy is more than $1 \mathrm{MeV}$, the escape of the recoiled protons becomes non-negligible. In the neutron energy region greater than $7.5 \mathrm{MeV}$, other processes (elastic recoil and $(\mathrm{n}, \alpha)$ reaction of the heavy nucleus) are dominant. In the case of $14.1 \mathrm{MeV}$ neutrons, the calculated average energy deposition per incident neutron is $1.3 \mathrm{keV}$ (corresponds to $1.43 \times 10^{-4} \mathrm{PSL} /$ neutron when $\mathrm{w}=4.125 \mathrm{MeV}$ and $\mathrm{L}=$ $60 \mu \mathrm{m})$. The measured neutron sensitivity $\left(1.3 \times 10^{-4} \mathrm{PSL} /\right.$ neutron $)$ is consistent with this Monte Carlo model.

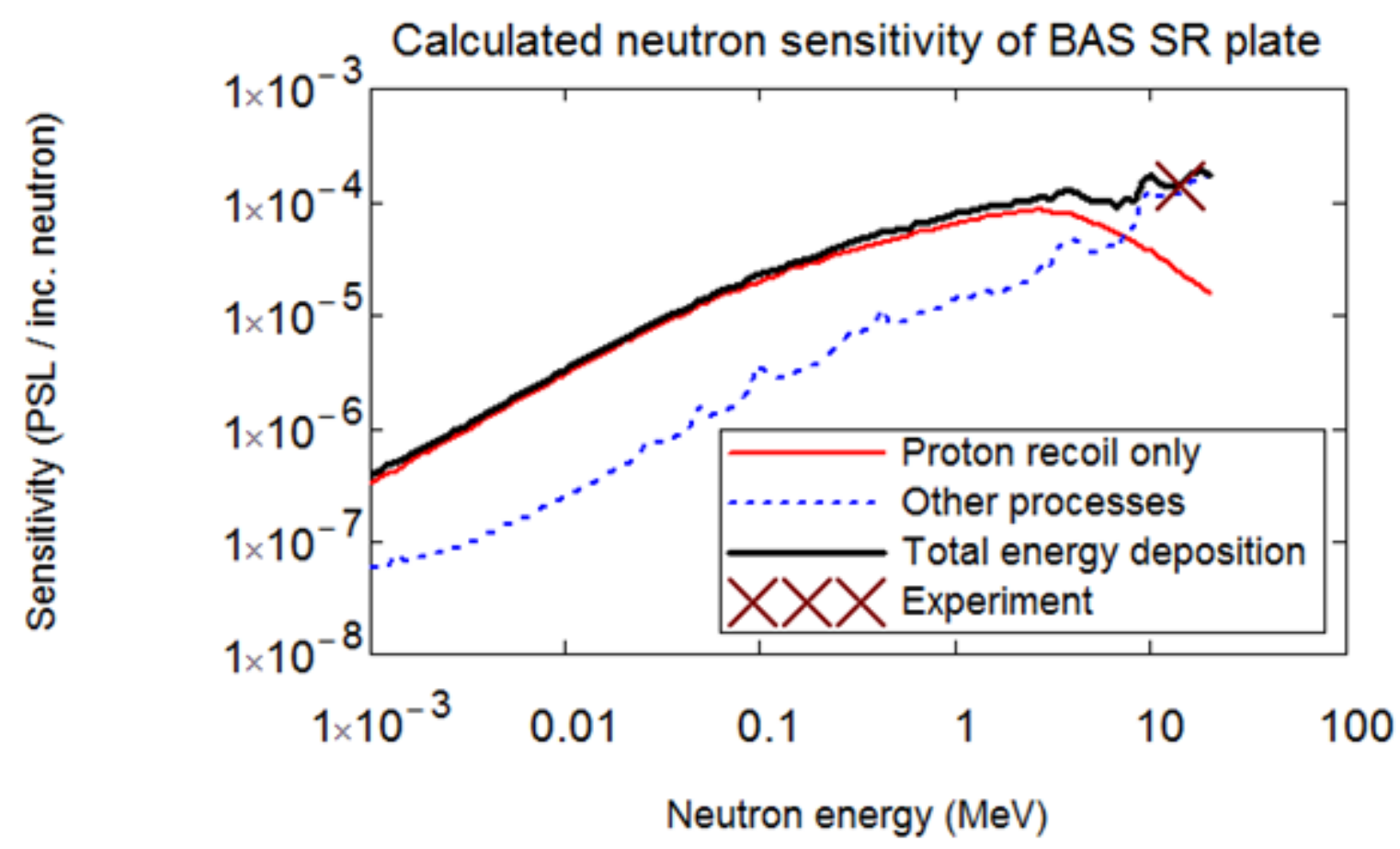

Fig. 5. Calculated neutron sensitivity of the imaging plate (BAS SR). The energy deposition due to proton recoil in the phosphor was calculated by a Monte Carlo code based on the SRIM2000. The energy deposition due to other mechanisms was calculated by the MCNP5. The calculated sensitivity was consistent with data at $14 \mathrm{MeV}$.

\section{SUMMARY}

$\mathrm{X}$-ray and neutron sensitivities of the imaging plate (BAS SR) were measured. The observed $\mathrm{x}$-ray sensitivity was $1.38 \times 10^{-3} \mathrm{PSL} /$ photon for $5.9 \mathrm{keV}, 1.54 \times 10^{-3} \mathrm{PSL} /$ photon for $22 \mathrm{keV}$, and $0.89 \times 10^{-3} \mathrm{PSL} / \mathrm{photon}$ for $59 \mathrm{keV}$. The neutron sensitivity was $1.4 \times 10^{-4} \mathrm{PSL} /$ neutron at $14.1 \mathrm{MeV}$. The observed $\mathrm{x}$-ray and neutron sensitivity was consistent with a model incorporating MCNP and SRIM.

\section{ACKNOWLEDGMENT}

Lawrence Livermore National Laboratory is operated by Lawrence Livermore National Security, LLC, for the U.S. Department of Energy, National Nuclear Security Administration under Contract No. DE-AC52-07NA27344. 


\section{REFERENCES}

[1] Y. Amemiya, et al., Nucl. Instrum. Methods Phys. Res. A 266, 645 (1988).

[2] N. Izumi, R. Snavely, G. Gregori, et al., Rev. Sci. Instrum. 77, 10 E325 (2006).

[3] B. R. Maddox, et al., Rev. Sci. Instrum. 82, 023111 (2011).

[4] N. Izumi, et al, Rev. Sci. Instrum. 83, 10E121 (2012).

[5] T. Ma, et al, Rev. Sci. Instrum, 83, 10E115 (2012).

[6] Y. Iwabuchi, et al., Jpn. J. Appl.Phys. 33, 175 (1994).

[7] J. S. Hendricks, et al., "MCNPX Version 26B," LA-UR-06-3248, Los Alamos National Laboratory (2006).

[8] M. Thoms, Nucl. Instr. and Meth. in Phys. Res. A 378, 598 (1996).

[9] J. M. Soures et al., Phys. Plasmas 3, 2108 (1996)

[10] V. Yu. Glebov, et al., Rev. Sci. Instrum. 72, 824 (2001).

[11] X-5 Monte Carlo Team, LA-UR-03-1987. Los Alamos National Laboratory (revised 2008).

[12] J.F. Ziegler, M.D. Ziegler and J.P. Biersack, SRIM-2008 Computer Code, Version SRIM2008.03, 2008. 